\title{
A Stochastic Unit Commitment Model for a Local CHP Plant
}

\author{
Hans F. Ravn, Jannik Riisom, and Camilla Schaumburg-Müller
}

\begin{abstract}
Local CHP development in Denmark has during the 90's been characterised by large growth primarily due to government subsidies in the form of feed-in tariffs. In line with the liberalisation process in the EU, Danish local CHPs of a certain size must operate on market terms from 2005.

This paper presents a stochastic unit commitment model for a single local CHP plant (consisting of CHP unit, boiler, and heat storage facility) which takes into account varying spot prices. Further, additional technology is implemented in the model in the form of an immersion heater.

Simulations are conducted using the spot prices of the years 2001-2003, both with and without the immersion heater included in the model, and the results are compared to the full information case.
\end{abstract}

Index Terms - combined heat and power, Denmark, market conditions, power generation dispatch, stochastic programming

\section{CONTENTS}

\section{Introduction}

II Uncertainties when bidding to the spot market

III Unit commitment model

IV Immersion heater

V Simulations

VI Conclusions

\section{References}

Biography

Biography

Biography

\section{INTRODUCTION}

In Denmark, the development of local combined heat and power (CHP) plants has been characterised by large growth throughout the nineties (cf. Figure 1), based in part on government subsidies in the form of feed-in tariffs. In 2003, local CHP production in Western Denmark constituted almost a quarter of the total electricity production [4]. Simultaneously, there

\footnotetext{
H.F. Ravn is with RAM-løse edb, Smørum, Denmark (hansravn@aeblevangen.dk).

J. Riisom is with Københavns Energi, Copenhagen, Denmark (jari@ke.dk).

C. Schaumburg-Müller is with the Department of Operations Research, Technical University of Denmark, Denmark (csm@imm.dtu.dk).
}

has been a significant growth of wind power, particularly in the Western Danish system. As both the power produced by the local CHPs and the wind power are prioritised, the production of these types of power is occasionally sufficient to meet the total demand in the system, causing the market price of electricity to drop dramatically, sometimes even to zero-level.

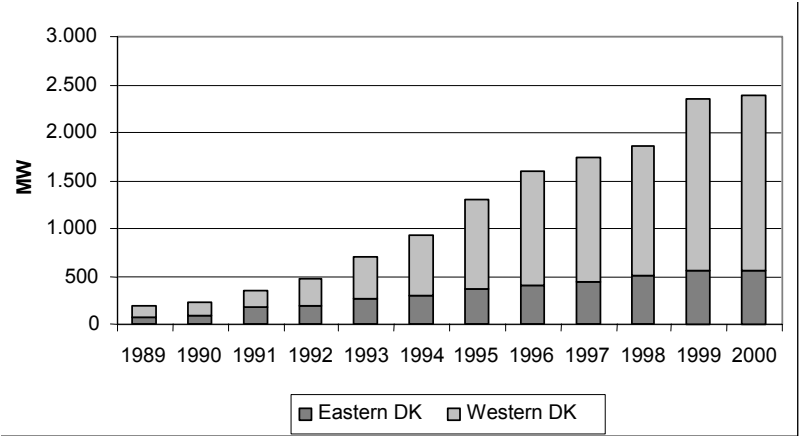

Fig. 1. Growth in Danish local CHP during the nineties.

In line with the liberalisation process of the energy sectors of the EU countries, present Danish legislation states that local

$4 \mathrm{CHP}$ are to begin operating on market conditions in the year 2005 [1].

5 This means that the income that the local CHPs previously gained from selling electricity at the feed-in tariff (cf. Figure 2)

6 is replaced in part by income gained from selling electricity on the Nordic (Denmark, Sweden, Norway, Finland) spot market, Nord Pool [6]. In addition a subsidy independent of production level will be obtained. Thus, the electricity production quantities of the local CHPs will depend on the market price.

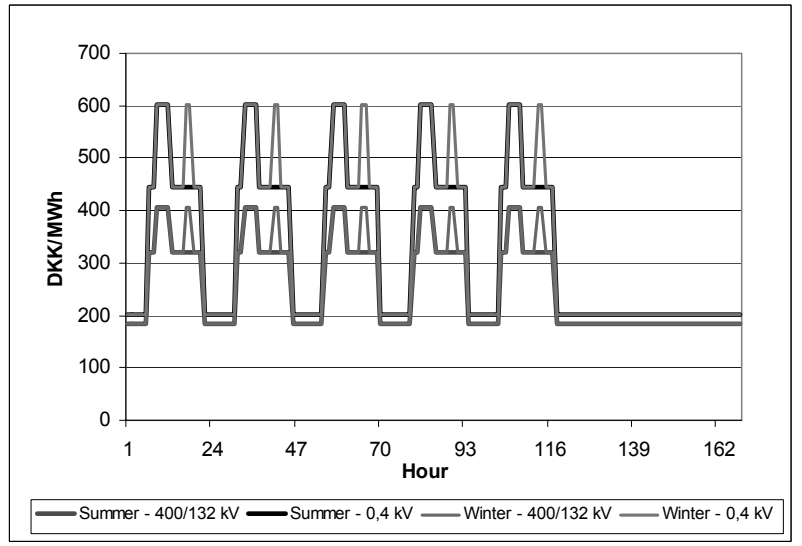

Fig. 2. The Danish three-stage tariff during a week. 
Recent work has considered the problem of optimal bidding from an overall point of view [8], derived conditions for the existence of an optimal supply function while modelling competition using an appropriate probability distribution [2], or produced offer stacks for a single generator based on dynamic programming [5].

In this paper, the situation is considered from the point of view of a local CHP plant, which must make bids to the Nordic electricity exchange in accordance with the rules of the Nord Pool 24-hour cycle. Thus, bids are made at a time where spot prices are unknown and this fact must be taken into account when modelling, resulting in the stochastic unit commitment model presented. As the model only considers a local CHP plant, it is reasonable to assume that the plant is price taking in the market and thus has no direct influence on the spot price. To illustrate the workings of the model, simulation results are included for the years 2001-2003.

\section{UNCERTAINTIES WHEN BIDDING TO THE SPOT MARKET}

Each day before noon the local CHP plant bids electricity prices and volumes to the Nordic electricity exchange, Nord Pool [6]. The plant is assumed to be a price taker on the market and the hourly spot prices for the following day are, as mentioned above, unknown at the time of the bidding.

The model presented in this paper considers the problem taking into account various spot price scenarios, $s$, where $\pi_{t}^{s}, t=$ $1, \ldots, T, s=1, \ldots, S$ indicates the spot price for hour $t$ in scenario $s$. A spot price scenario consists of a series of $T$ spot prices (e.g. based on historical data), where $T$ typically is a multiplum of 24. Each scenario $s$ occurs with a probability represented by the non-negative parameter $\phi^{s}$. In this paper, historical data from Nord Pool was used (see Section V).

In the simple model presented in the previous paper [7], a two-level price structure was introduced. The prices $p_{1}$ resp. $p_{2}$ indicated the surplus cost of producing electricity when the heat produced simultaneously could be utilised resp. when it could not (note, that $p_{1}<p_{2}$ ). When spot prices were expected to be below $p_{1}$ nothing was bid to the spot market; were the spot prices expected to be above $p_{2}$ full capacity was bid; and were the spot prices expected to be between $p_{1}$ and $p_{2}$ the model would determine a suitable bid depending on the heat demand.

This simple approach may be less than expedient in certain cases. For instance, consider the case illustrated in Figure 3: here the two-price model enforces a shut-down in the intermediate period with low prices (below $p_{1}$ ) where it might be more desirable to continue production undeterred throughout the whole nine-hour period, e.g. if the start-up cost of the CHP unit is higher than the cost of producing during the low price period.

Alternatively, in order to handle situations as the example given above, define price levels for bids that adapt to the hourly spot prices. Consider a situation with e.g. five different spot price scenarios for a given hour, where $\pi^{1}<\pi^{5}<\pi^{3}<\pi^{2}<$ $\pi^{4}$. In that case, six ordering levels are needed: one level below all spot prices (level $o=1$ ), one level above all spot prices (level $o=6$ ), as well as four intermidiate levels (levels $o=$ $2, \ldots, o=5$ ). The parameter $\delta_{o t}^{s}$ is used to keep track of the

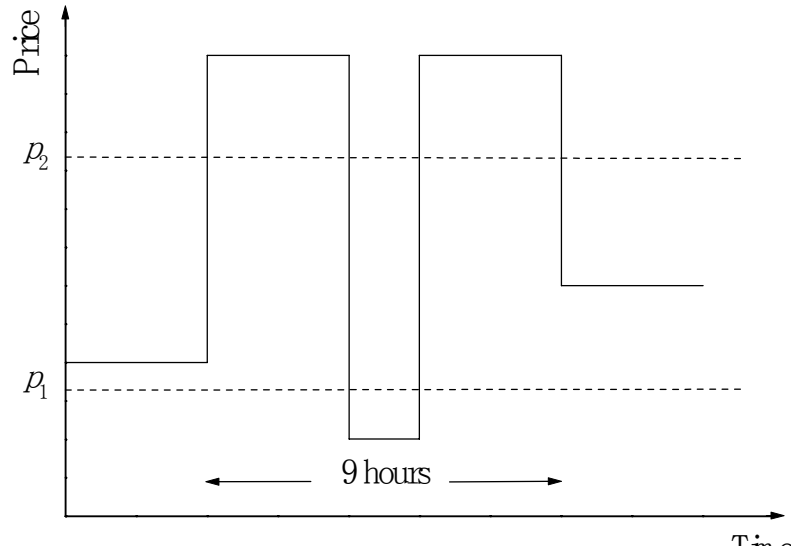

Time

Fig. 3. In the simple case, nothing is bid in the period with prices below $p_{1}$.

order of the spot prices $\pi_{t}^{s}$ for each hour, and is defined as

$$
\delta_{o t}^{s}= \begin{cases}1, & \text { if scenario } s \text { has order } o \text { in hour } t \\ 0, & \text { else }\end{cases}
$$

where $t=1, \ldots, T, s=1, \ldots, S$, and $o=1, \ldots, S+1$.

Each hourly price level has an associated bid volume, $m_{o t}$, measured in $M W h_{\text {heat }}$. Figure 4 illustrates the case with five ordered spot prices for a single hour.

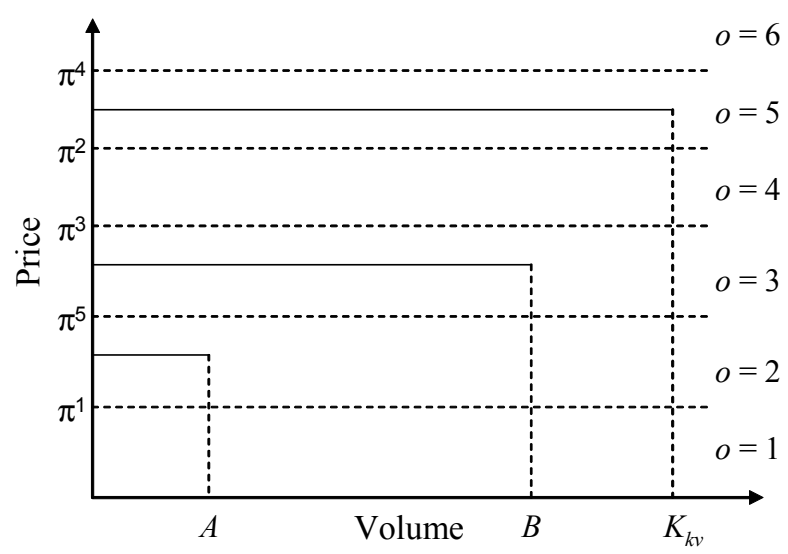

Fig. 4. Ordering of spot prices for a single hour with associated total bid volumes.

The level below the lowest spot price $\pi^{1}$ (i.e. the first expected spot price for the hour in question) has order 1 . This level is too low for the plant manager to willingly bid any volume (i.e. lower than the marginal production cost on the CHP unit). Once the price exceeds the spot price $\pi^{1}$ and enters level 2 , the plant manager is willing to bid the volume $A$. When the price exceeds the fifth expected spot price, $\pi^{5}$, and reaches spot price level 3, the plant manager is willing to bid the total volume $B$. The full capacity, $K_{k v}$, of the CHP unit is not bid before the second expected spot price, $\pi^{2}$, is exceeded (i.e. level 5 is reached).

Note, that

- $\delta_{1 t}^{s}=1$ for all $s$ and $t$, as all spot price scenarios have at least order 1; 
- $\delta_{S+1, t}^{s}=0$ for all $s$ and $t$, as no spot price scenario will ever have order $S+1$.

\section{UNIT COMMITMENT MODEL}

The model presented in this paper considers a local CHP plant with a power generation unit (in the following termed the CHP unit), which generates heat as a by-product, a boiler, which produces heat only and a heat storage facility. A basic model which handles bidding to the spot market while taking into account constraints regarding production and minimising costs was presented in [7]. It is this basic model which has been expanded upon in this paper by including a unit commitment aspect and startup costs for the CHP unit as well as introducing a new technical tool: an immersion heater, which uses electricity (when prices are low) to produce heat and thus may be seen as a way of storing electricity.

Most Danish local CHP plants started out as heat plants and still have a local heat demand that must be met. The heat demand for period $t$ is included in the model as $d_{t}$. The electricityto-heat ratio for the CHP unit (in the following termed the back pressure value) is denoted $c_{m}$, and indicates that $1 \mathrm{MWh}$ heat is produced when producing $c_{m}$ MWh power.

In the following, $c^{k v}, c_{\text {start }}^{k v}$, and $c^{k}$ denote, in turn, production costs for the CHP unit, starting costs for the CHP unit, and production costs for the heat boiler. Further, $K_{k v}$ and $K_{k}$ represent the maximum production capacity for the CHP unit and the boiler, respectively. Finally, $V_{t}^{s}$ is the volume of heat in the heat storage facility at the beginning of period $t$ in scenario $s$ and $V_{\max }$ is the maximum capacity of the heat storage.

Firstly, it must be ensured that the heat produced meets the demand in all periods, which the following constraints handle.

$$
\begin{aligned}
V_{t+1}^{s} & =V_{t}^{s}+\sum_{o} m_{o t} \delta_{o t}^{s}+m_{k t}^{s}-d_{t}, \\
\forall s, t & =1, \ldots, T-1 \\
V_{1}^{s} & =V_{T}^{s}+\sum_{o} m_{o T} \delta_{o T}^{s}+m_{k T}^{s}-d_{T}, \forall s
\end{aligned}
$$

The constraints state that the amount of heat in the storage at the beginning of the following period should equal the heat in the storage at the beginning of the present period, as well as the heat produced on the CHP unit and the boiler, once heat demand has been met.

Now, let $m_{\text {min }}$ denote the minimum production on the CHP unit. Thus, production in every hour must be either 0 or at least $m_{\min }$. To ensure this, the binary variable $z_{t}^{s}$ is introduced, which is 1 when there is production on the CHP unit and 0 otherwise. Thus the production capacity constraints for the CHP unit may be written as

$$
z_{t}^{s} m_{\min } \leq \sum_{o} m_{o t} \delta_{o t}^{s} \leq z_{t}^{s} K_{k v}, \quad \forall s, t
$$

The structure of the constraint is illustrated in Figure 5.

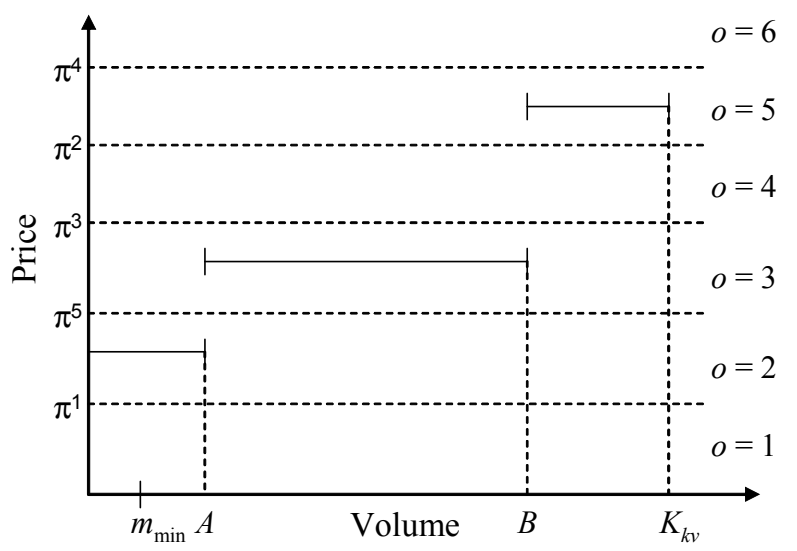

Fig. 5. Ordering of spot prices for a single hour with associated bid volumes.

In this case, $m_{2 t}^{1}=A, m_{3 t}^{5}=B-A$, and $m_{5 t}^{2}=K_{k v}-B$, where $K_{k v}$ is the maximum capacity of the CHP unit. This is in accordance with constraint (3), as $A+(B-A)+\left(K_{k v}-B\right)=$ $K_{k v}$ and $m_{\min }<A$.

The non-negative variable $v_{t}^{s}$ indicates whether the CHP unit was started during period $t$ in scenario $s$ and is ensured binary by the optimisation and the constraint

$$
v_{t}^{s} \geq z_{t}^{s}-z_{t-1}^{s}, \quad \forall s, t=2, \ldots, T
$$

In order to handle the initial period, the binary parameter $z_{\text {init }}$ is defined, indicating whether the CHP unit was running in the period immediately prior to the time considered. This leads to the inclusion of the constraint

$$
v_{1}^{s}=z_{1}^{s}-z_{\text {init }}, \quad \forall s
$$

Starting and stopping characteristics may be implemented similarly for the boiler but is of less interest and thus left out in this paper.

Finally, the capacity restrictions for both the boiler and the heat storage facility must be respected, which leads to the following constraints:

$$
\begin{aligned}
0 & \leq m_{k t}^{s} \leq K_{k}, \quad \forall s, t \\
0 & \leq V_{t}^{s} \leq V_{\max }, \quad \forall s, t \\
z_{t}^{s} & \in\{0,1\}, m_{o t}, v_{t}^{s} \geq 0, \quad \forall o, s, t
\end{aligned}
$$

The problem, prior to introducing the immersion heater, now amounts to minimising the sum of the cost of expected production and startup costs while subtracting expected profits from electricity sales, i.e. minimising the expression:

$$
\begin{aligned}
\sum_{s, t} \phi^{s} & \left\{c^{k v} \sum_{o} m_{o t} \delta_{o t}^{s}+m_{k t}^{s} c^{k}\right. \\
& \left.+c_{\text {start }}^{k v} v_{t}^{s}-\pi_{t}^{s} c_{m} \sum_{o} m_{o t} \delta_{o t}^{s}\right\}
\end{aligned}
$$

subject to the constraints (1)-(8)

The output produced by the model is a production plan in terms of heat volumes for both the CHP unit and the boiler. 
This is then translated to an electricity supply function via the electricity-to-heat ratio, $c_{m}$, for the CHP unit. The size of the model (1)-(9), which thus may be chategorised as a stochastic integer LP problem, depends on several factors such as the specifications of the plant to which it is applied, the number of spot price scenarios included, as well as the time horizon for which the model is run.

\section{IMMERSION HEATER}

In line with the new legislation it may become permissible to use an immersion heater as a way of producing heat for the heat storage facility by use of electricity. This would primarily be in the case where electricity prices are particularly low (read: lower than heat production costs on the boiler and/or the CHP unit). Thus the model can contain up to three different heat production technologies: combined heat and power unit, heat boiler, and immersion heater. The interconnection between these technologies is illustrated in Figure 6 where the marginal costs of the technologies are depicted (note that start-up costs are disregarded).

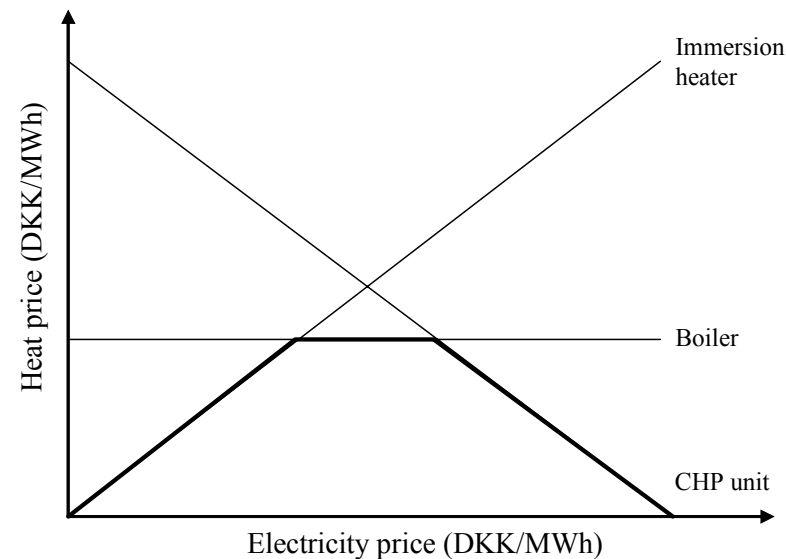

Fig. 6. Illustration of the influence of the immersion heater. Production is marked by the bold line.

The figure may be interpreted as follows: When the price of electricity is low, it is cheap to produce heat using the immersion heater and expensive to produce heat using the CHP unit, and vice versa when the price of electricity is high (in which case heat production on the CHP unit is compensated by the high price attained for electricity produced simultaneously). The cost of producing heat on the boiler is constant, regardless of the price of electricity. Similarly, fuel prices are assumed constant.

The heat production pattern distributed on the three technologies is therefore simple to determine. Production is placed on the immersion heater when the electricity price is low. If the boiler cost is sufficiently low, the boiler takes over heat production resulting in a medium level price (the horizontal bold line on Figure 6), whereafter the CHP unit takes over production once the electricity price is sufficiently high. In some cases the boiler cost may be so high that no boiler production takes place and the demanded heat is produced solely by the immersion heater and the CHP unit (in such cases, the horizontal boiler cost lies above the cross between the costs of the immersion heater and the CHP unit).

It should be obvious that the combination of the three technologies will have a stabilising effect on the electricity spot prices. For instance, consider the case where all Western Danish local CHP plants (which constitute nearly $25 \%$ of the total electricity production in that area, cf. Section I) have immersion heaters or similar technological means for electricity-toheat conversion. If spot prices are very high they are all interested in producing electricity for sale on the market, and if prices are low they all buy electricity to convert to heat. When such a large percentage of the producers act in the manner described it must invaribly stabilise the spot prices by helping to eliminate price spikes and extreme low price periods.

The modelling of the immersion heater is analogous to that of the CHP unit. Let $e_{o t}$ represent the volume of electricity purchase offered at the spot price $\pi_{t}^{s}$ with order $o$. Note, that the binary used to indicate whether electricity is bought is $\left(1-\delta_{o t}^{s}\right)$ and thus the reverse of the indicator for electricity production. The electricity-to-heat conversion rate is termed $c_{e}$. For the sake of simplicity, it is assumed that $c_{e}=1$, i.e. there is direct conversion from electricity to heat, however any other electricity-to-heat conversion technology, e.g. a heat pump, may be used - the difference is simply a question of changing the size of the conversion rate $c_{e}$. Due to the nature of $\delta$, it holds that

- $\left(1-\delta_{1 t}^{s}\right)=0, \forall s, t$ as it is impossible to buy electricity cheaper than the lowest spot price scenario;

- $\left(1-\delta_{S+1, t}^{s}\right)=1, \forall s, t$, i.e. for all scenarios the offer to buy is accepted.

The cost of buying electricity for heat production must of course be deducted in the objective function and capacity constraints for the immersion heater must be included in the model. Further, the amount of heat produced by the immersion heater must be included in the storage constraints (1) and (2). Revising the model in accordance with these statements implies minimising the expression

$$
\begin{aligned}
& \sum_{s, t} \phi^{s}\left\{\left(c^{k v}-\pi_{t}^{s} c_{m}\right) \sum_{o} m_{o t} \delta_{o t}^{s}+m_{k t}^{s} c^{k}\right. \\
& \left.+c_{\text {start }}^{k v} v_{t}^{s}+\pi_{t}^{s} \sum_{o} e_{o t}\left(1-\delta_{o t}^{s}\right)\right\}
\end{aligned}
$$

subject to the storage and capacity constraints

$$
\begin{aligned}
& V_{t+1}^{s}=V_{t}^{s}+\sum_{o} m_{o t} \delta_{o t}^{s}+m_{k t}^{s}-d_{t} \\
& \quad+\sum_{o} e_{o t}\left(1-\delta_{o t}^{s}\right), \quad \forall s, t=1, \ldots, T-1 \\
& V_{1}^{s}=V_{T}^{s}+\sum_{o} m_{o T} \delta_{o T}^{s}+m_{k T}^{s}-d_{T} \\
& \quad+\sum_{o} e_{o T}\left(1-\delta_{o T}^{s}\right), \quad \forall s \\
& 0 \leq \sum_{o} e_{o t}\left(1-\delta_{o t}^{s}\right) \leq e_{\max }, \quad \forall s, t
\end{aligned}
$$

as well as the constraints (3)-(8). Note, that because it is assumed that the conversion rate of the immersion heater is 
$c_{e}=1$, the volume $\sum_{o} e_{o t}\left(1-\delta_{o t}^{s}\right)$ may both symbolise a heat or an electricity volume, according to necessity.

\section{Simulations}

This paper illustrates the above mentioned characteristics by including simulation results achieved by applying the models (1)-(9) (without immersion heater), and (3)-(8) and (10)-(13) (with immersion heater) using data for a local CHP plant located in Western Denmark. The plant has a boiler capacity of $K=23.2 \mathrm{MWh}$, heat capacity of $K_{k v}=2.392 \mathrm{MWh}$ and an electricity capacity of $2.028 \mathrm{MWh}$ on the CHP unit, and the capacity of the heat storage facility is $V_{\max }=25 \mathrm{MWh}$. The total heat demand over a year is approximately $15 \mathrm{GWh}$ with clear seasonal variations (i.e. high in winter, low in summer).

The spot price scenarios used were based on the actual Western Danish spot prices of 2001-2003. The daily mean spot prices for the years simulated are shown in Figure 7.

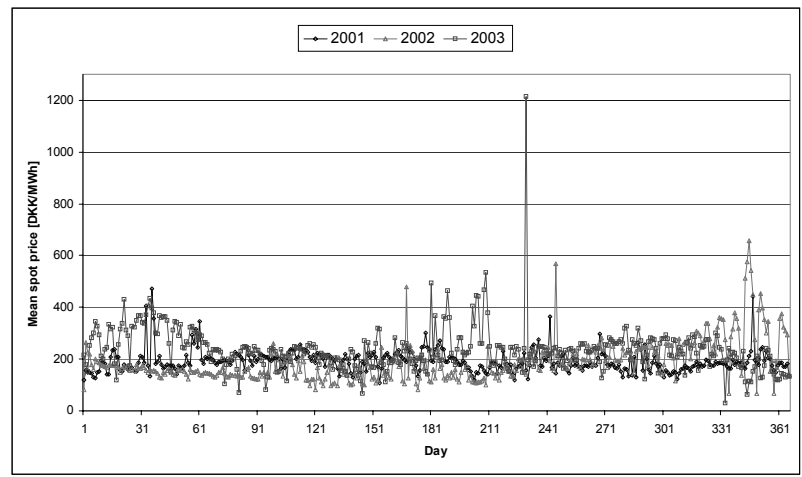

Fig. 7. The daily mean spot prices for the years 2001-2003.

In the Nordic system hydro power accounts for about half of the electricity production hence the electricity prices will depend heavily on the amount of hydro power available. The year 2001 was fairly normal with no extreme oscillations. The typical spot prices were in the range $150 \mathrm{DKK} / \mathrm{MWh}$ to 300 $\mathrm{DKK} / \mathrm{MWh}$, with typical daily and weekly variations, and with no clear trend from beginning to end of the year.

The year 2002 was a dry year in the Nord Pool area, i.e. less hydro power was available than usual, which caused the general rising trend in the prices towards the end of the year, beginning at the level of 2001, and ending at a level around 400 DKK/MWh to 600 DKK/MWh.

In the beginning of 2003, the last effects of the dry year 2002 could still be seen, whereafter the prices stabilised at the level of approximately $250 \mathrm{DKK} / \mathrm{MWh}$ during the spring. However, over the summer prices fluctuated significantly with an extreme peak occurring in September. Finally, towards the end of the year, prices began to fall as spring was approached with its expected large inflow.

Thus, the three years display marked individual characteristics concerning the general trend of the price level within a year. However, the daily and weekly variations remained more stable, although price spikes (the highest was $4430 \mathrm{DKK} / \mathrm{MWh}$ - nearly 18 times the typical level) were observed as previously noted.
The spot price scenarios in the models (1)-(9) (without immersion heater), and (3)-(8) and (10)-(13) (with immersion heater) were constructed in the following way. For any given day the set of scenarios consisted of the spot prices of $N$ previous days (with equal probability) as well as an artificial high price scenario with a small probability. The latter ensured that some bid was made in the unlikely event that the $N$ previous days all consisted of exeptionally low spot prices. Further, the spot price level was varied by adding (or subtracting) some positive amount, e.g. $50 \mathrm{DKK} / \mathrm{MWh}$, from all the yearly spot prices. This variation of the spot price level is justified by the aforementioned characteristics of the simulated years (although the ranges selected for the variations is unrealistically large, this is to display more clearly the asymptotic behaviour of the results).

Simulating both with and without the immersion heater (IH) for each year, yields six cases in total, which were implemented using GAMS [3]. The various simulation cases are named in Table I.

TABLE I

SiMULATION CASES WITH AND WITHOUT IMMERSION HEATER.

\begin{tabular}{c|c|c}
\hline Year & Without IH & With IH \\
\hline 2001 & A & B \\
\hline 2002 & C & D \\
\hline 2003 & E & F \\
\hline
\end{tabular}

All cases were simulated with $N=3, N=5$, and $N=$ 7. The results were in each case compared to the case where the prices were known in advance (the full information case). This yielded the differences depicted in Figures 8, 9, and 10, respectively.

All three figures have been deliberatly truncated so the differences for the levels below $+500 \mathrm{DKK} / \mathrm{MWh}$ may be seen clearly. The values for the two truncated spot price levels, +500 $\mathrm{DKK} / \mathrm{MWh}$ and $+2000 \mathrm{DKK} / \mathrm{MWh}$, were approximately 7 million DKK and 25 million DKK, respectively, for all the tested instances of $N$.

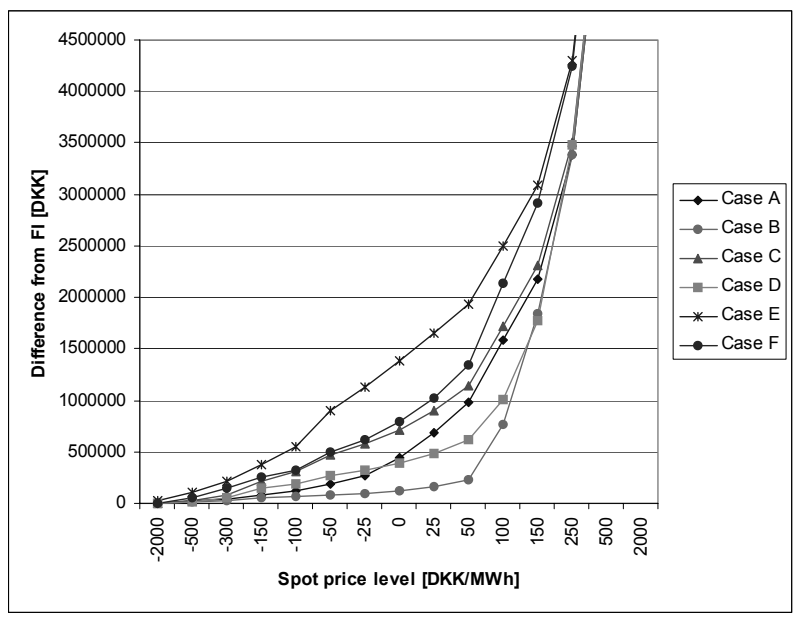

Fig. 8. Difference between the full information case and the stochastic case after simulation of cases A-F with varying spot price levels and $N=3$. 


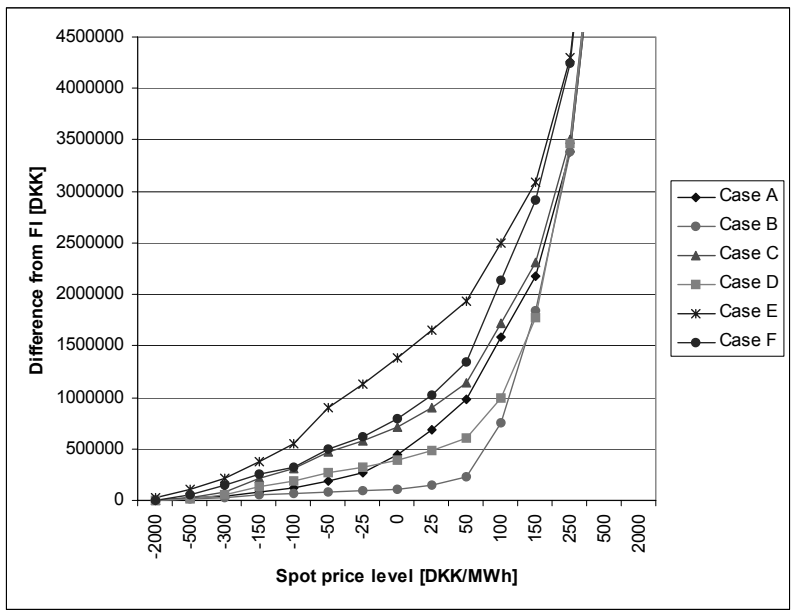

Fig. 9. Difference between the full information case and the stochastic case after simulation of cases A-F with varying spot price levels and $N=5$.

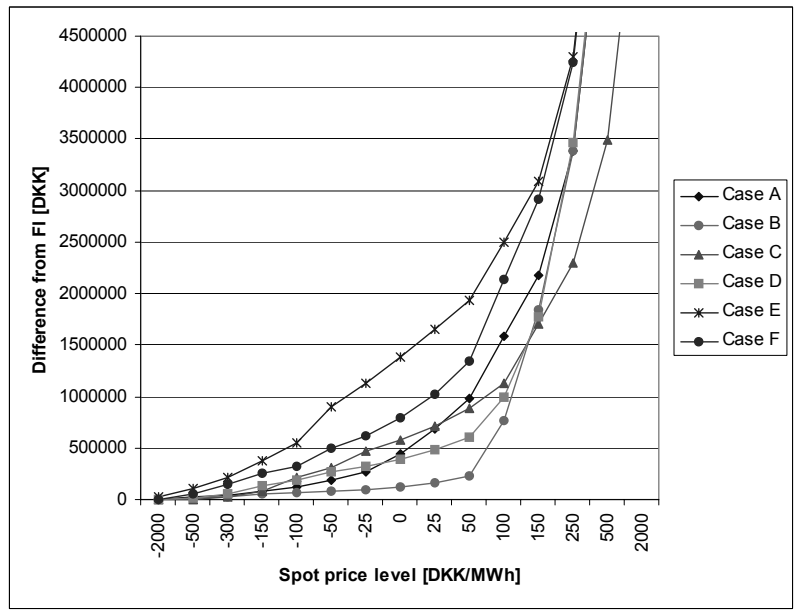

Fig. 10. Difference between the full information case and the stochastic case after simulation of cases A-F with varying spot price levels and $N=7$.

One interesting aspect, which is evident in all three figures, is that for each of the simulated years the cases in which the immersion heater is included $(\mathrm{B}, \mathrm{D}, \mathrm{F})$ have smaller errors than the corresponding cases without the immersion heater (A, C, E), the single exception being for $N=7$ where cases C and D (2002) cross paths around the level $+150 \mathrm{DKK} / \mathrm{MWh}$. From the point of view of a single CHP plant the presence of an immersion heater (or similar technology) thus has a stabilising effect on the total cost. This goes well in conjunction with the statement from Section IV that the relationship between CHP production and heat production via conversion technologies should stabilise the market prices somewhat in the long run.

The size of the error compared to the total cost varies significantly from year to year in the middle range cases, i.e. the interval $\pm 150 \mathrm{DKK} / \mathrm{MWh}$. For $N=5$ at the neutral spot price level $(+0 \mathrm{DKK} / \mathrm{KWh})$ it is $4 \%$ with $\mathrm{IH}$ and $8,5 \%$ without in $2001,15 \%$ with IH and $14 \%$ without in 2002 , and $23 \%$ with IH and $27 \%$ without in 2003 . This confirms the analysis of the different characteristics in the three years, cf. the descriptions on page 5. 2001 was the 'standard' year, 2002 had the rising trend but was otherwise fairly stable, and 2003 had several volatile periods with significant price spikes.

\section{CONCLUSIONS}

A stochastic unit commitment model for a single local CHP plant consisting of a CHP production unit, a boiler, and a heat storage facility was presented in the paper. The model takes into account varying spot prices as well as starting costs on the CHP unit. The possibility of including extra technology in the form of an immersion heater or similar technology which transforms electricity to heat was also implemented in the model.

Simulations were conducted for the years 2001-2003 using actual data from a Western Danish local CHP plant and the spot prices for Western Denmark during that period. The simulations considered the situation both with and without the inclusion of the immersion heater.

From the simulation results it was seen that the inclusion of the immersion heater helped reduce uncertainty, as the difference between the simulated cases and the full information case dropped with up to more than $4 \%$ of the total cost. Additionally, the characteristics of the three years simulated described early in Section $\mathrm{V}$ were represented in the way the size of the error compared to the total cost differed from year to year.

An avenue for further research would be to consider more than one plant in the model. One perspective that arises from such an avenue is the possibility of looking at the entire Western Danish local CHP system, i.e. by aggregating the model using available data of the distribution of different CHP technologies and their characteristics.

\section{REFERENCES}

[1] Aftale om Vindenergi og Decentral Kraftvarme (Agreement about Wind Energy and Local Combined Heat and Power), The Danish Energy Agency, http://www.ens.dk (2004)

[2] Anderson EJ, Philpott AB, "On Supply Function Bidding in Electricity Markets" in Decision Making Under Uncertainty: Energy and Environmental Models, F. Auzerais, R. Burrage, G. Greengard, A. Ruszczynski, Eds., Springer-Verlag 2002

[3] Brooke A, Kendrick D, Meeraus A, Raman R, GAMS - A User's Guide, http://www.gams.com

[4] Eltra, the Western Danish independent system operator (http://www.eltra.dk)

[5] Neame P, Philpott AB, Pritchard G, Offer Stack Optimisation in Electricity Pool Markets, Operations Research vol. 51, No.3, pp.397-408, 2003

[6] Nord Pool, the Nordic Electricity Exchange (http://www.nordpool.no)

[7] Ravn H, Riisom J, Schaumburg-Müller C, Straarup SN, "Modelling Danish Local CHP on Market Conditions", Proc. $20046^{\text {th }}$ IAEE European Conference: Modelling in Energy Economics and Policy

[8] Wen F, David AK, Coordination of Bidding Strategies in Day-Ahead Energy and Spinning Reserve Markets, Electrical Power and Energy Systems vol. 24, pp. 251-261, 2002 


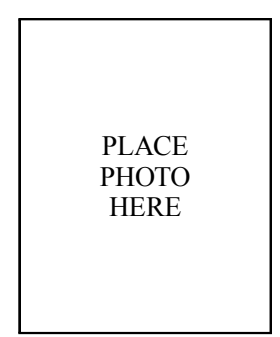

Hans F. Ravn is M.Sc. in Engineering, Ph.D. and Dr.Techn. from the Technical University of Denmark. His fields of work are mathematical modelling and energy systems. He has worked with the Danish Energy Agency, the Technical University of Denmark, Risø National Laboratory, IEE in México and a Danish TSO. He now has his own consulting company RAM-løse edb.

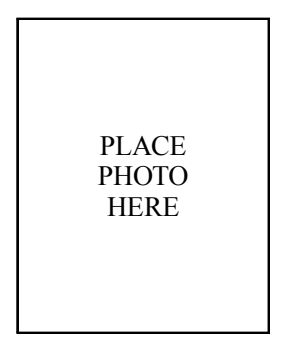

Jannik Riisom is M.Sc. in Mathematics and Economy from the University of Copenhagen, and his field of work is mathematical modelling. He has worked as a research assistent at the Technical University of Denmark and now works at the Danish energy company Københavns Energi.

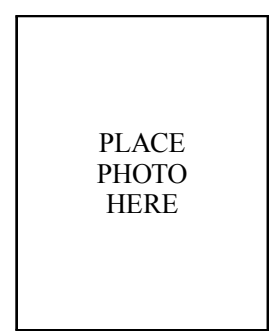

Camilla Schaumburg-Müller is M.Sc. in Mathematics and Economy from the University of Copenhagen. She specialises in mathematical modelling with emphasis on the energy sector. She has worked as a research assistent at the Technical University of Denmark and is presently pursuing a Ph.D. degree, also at the Technical University of Denmark. 